\title{
DESIGN OF LOW-COST IONIC LIQUIDS FOR LIGONCELLULOSIC BIOMASS PRETREATMENT
}

\author{
A. George ${ }^{1}$, A. Brandt ${ }^{2}$, S. M. S. Nizan S. Zahari ${ }^{3}$, D. Klein-Marcuschamer ${ }^{1}$, R. Parthasarathi ${ }^{1}$,

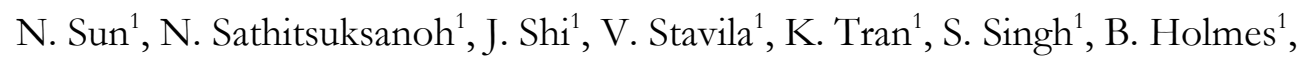 \\ T. Welton ${ }^{3}$, B.A. Simmons ${ }^{1}$, J.P. Hallett ${ }^{2, *}$ \\ ${ }^{1}$ Joint BioEnergy Institute, Emeryville, California, United States \\ ${ }^{2}$ Department of Chemical Engineering, Imperial College, London, United Kingdom \\ ${ }^{3}$ Department of Chemistry, Imperial College, London, United Kingdom \\ *i.hallett@,imperial.ac.uk
}

\begin{abstract}
The cost of ionic liquids (IL) is one of the main impediments to IL utilization in the cellulosic biorefinery, especially in the pretreatment step. In this study, a number of ionic liquids were synthesized with the goal of optimizing solvent cost and stability whilst demonstrating promising processing potential. To achieve this, inexpensive feedstocks such as sulfuric acid and simple amines were combined into a range of protic ionic liquids containing the hydrogen sulfate $\left[\mathrm{HSO}_{4}\right]^{-}$anion. The performance of these ionic liquids was compared to a benchmark system containing the IL 1ethyl-3-methylimidazolium acetate $\left[\mathrm{C}_{2} \mathrm{C}_{1} \mathrm{im}\right][\mathrm{OAc}]$. The highest saccharification yields were observed for the triethylammonium hydrogen sulfate IL, which was $75 \%$ as effective as the benchmark system. Techno-economic modeling revealed that this promising and yet to be optimized yield was achieved at a fraction of the processing cost. This study demonstrates that some ILs can compete with the cheapest pretreatment chemicals, such as ammonia, in terms of effectiveness and process cost, removing IL cost as a barrier to the economic viability of IL-based biorefineries.
\end{abstract}

\section{INTRODUCTION}

The success of lignocellulosic biorefineries depends upon efficiently pretreating the feedstock in order to render its components cellulose, hemicellulose and lignin amenable to further processing. ${ }^{1-3}$ Ionic liquids (ILs) have proven to be promising pretreatment solvents. ${ }^{4}{ }^{5}\left[\mathrm{C}_{2} \mathrm{C}_{1} \mathrm{im}\right][\mathrm{OAc}]$, also known as [Emim][Ac], is one of the most intensively studied candidates for use in cellulosic bio-refineries. Its advantages include an effectiveness that is independent of biomass type, ${ }^{6-8}$ moderate reaction conditions in terms of time and temperature and high operating equipment compatibility. Additionally, $\left[\mathrm{C}_{2} \mathrm{C}_{1} \mathrm{im}\right][\mathrm{OAc}]$ has been shown to be both environmentally benign and compatible with organisms used for downstream conversion. ${ }^{9}{ }^{10}$ However, recent studies of its stability under 
process conditions have raised concerns about the suitability of this ionic liquid for biomass pretreatment, ${ }^{11}$ particularly in light of the high current cost of this and other ILs that have been suggested for biorefinery applications. ${ }^{12}$

One proven way to reduce this cost for multi-ton IL production is through the use of protic ILs (ILs with a protonated amine for a cation), as in the BASF BASIL process and indeed all large-scale IL industrial processes to date. ${ }^{13}$ This class of ILs is synthesized through simple neutralization of an organic amine with a mineral acid, to yield an IL that does not require purification. Hence protic ILs will be far less expensive than traditional dialkylimidazolium-based salts. For example, we recently estimated that bulk production of triethylammonium hydrogen sulfate $\left[\mathrm{HNEt}_{3}\right]\left[\mathrm{HSO}_{4}\right]$ will be as low as $\$ 1.24 \mathrm{~kg}^{-1} .^{14}$ The model also showed that any protic hydrogen sulfate IL will have its cost dominated by the choice of amine, due to the extremely low cost of bulk sulfuric acid and the simple synthesis. We also showed that due to the large reduction in synthetic steps (from 30 steps to 7) compared to $\left[\mathrm{C}_{2} \mathrm{C}_{1} \mathrm{im}\right][\mathrm{OAc}]$, the synthesis of protic ILs similar to $\left[\mathrm{HNEt}_{3}\right]\left[\mathrm{HSO}_{4}\right]$ is bound to have lower environmental impact due to a reduction in waste by-products, solvent losses, energy usage and $\mathrm{CO}_{2}$ generation.

We report here a study that was designed to identify low-cost ILs that would efficiently pretreat lignocellulose. ILs were designed with the goal that they should 1) enhance enzymatic hydrolysis, 2) work under hydrous conditions (20\% w/w water), 3 ) be thermally stable at processing conditions and 4) be cost effective. To assess this, we present enzymatic hydrolysis data, mass, lignin and glucan recovery data and crystallinity indices for switchgrass biomass treated with the chosen ionic liquids. We did not seek to optimize the processing conditions but to do a comparative study on a range of cost effective ILs in order to understand changes in performance based on structural changes and to benchmark this group of ILs against the widely used $\left[\mathrm{C}_{2} \mathrm{C}_{1} \mathrm{im}\right][\mathrm{OAc}]$. We also investigated IL peak decomposition temperatures and conducted a preliminary techno-economic analysis.

IL design rationale: The ILs were designed for this study on the basis that (i) ILs based on the hydrogen sulfate anion have proven to be effective delignifiers, (ii) protic cations in $\left[\mathrm{HSO}_{4}\right]^{-} \mathrm{ILs}$ appear to work as well as their non-protic analogues (iii) protic ILs can be produced more cheaply due to cheaper starting materials and ease of synthesis ${ }^{15}$, and (iv) many alkylamines are produced in large quantities at low cost today; ethyl- and ethanolamines are particularly attractive in this regard. The range of ionic liquids was selected so that the effect of number of alkyl chains could be investigated; therefore mono-, di-, and triethylammonium hydrogen sulfate were synthesized. Three further ILs had an $\mathrm{OH}$ group added to each alkyl chain, in order to study the effects of hydrogen bonding potential in the IL-biomass mixture. Finally, to investigate any steric effects, diisopropyl ammonium hydrogen sulfate was synthesized. Table 1 illustrates the structures of the ILs used. All of the ILs were tested as mixtures in 20\% water and compared with untreated biomass and the effect of the benchmark ionic liquid $\left[\mathrm{C}_{2} \mathrm{C}_{1} \mathrm{im}\right][\mathrm{OAc}]$, also containing $20 \%$ water.

\section{MATERIALS AND METHODS}


Detailed experimental procedures are given in the Supplementary Information. 1-ethyl-3methylimidazolium acetate, $\left[\mathrm{C}_{2} \mathrm{C}_{1} \mathrm{im}\right][\mathrm{OAc}]$, was purchased from Sigma-Aldrich while all other IL were synthesized according to procedures described in the ESI, similar to techniques described elsewhere. ${ }^{15}$ Switchgrass (Panicum virgatum) was provided by Dr Daniel Putnam, University of California at Davis. The air-dried biomass was milled by a Thomas-Wiley Mini Mill fitted with a 40mesh screen (Model 3383-L10 Arthur H. Thomas Co., Philadelphia, PA, USA) and sieved to the nominal sizes of 40-60 mesh $(250-400 \mu \mathrm{m})$. All feedstocks were further dried in a vacuum oven at 40 ${ }^{\circ} \mathrm{C}$ overnight prior to pretreatment to eliminate the variability of moisture content. All pretreatments were conducted in the presence of $20 \%$ water (w/w IL) and data compared to $\left[\mathrm{C}_{2} \mathrm{C}_{1} \mathrm{im}\right][\mathrm{OAc}]:\left[\mathrm{H}_{2} \mathrm{O}\right]$ $(4: 1 \mathrm{w} / \mathrm{w})$ by a methodology described elsewhere. ${ }^{16}$ The carbohydrate composition of biomass and residual biomass after hydrolysis was determined with a modified quantitative saccharification (QS) procedure. ${ }^{17}$ The standard NREL biomass protocol was used to measure lignin and ash ${ }^{18}$. All enzymatic hydrolysis experiments were conducted with $20 \mathrm{mg}$ protein (Novozymes Cellic ${ }^{\circledR}$ CTec 2) per gram of glucan. The XRD experiments were performed on a PANalytical Empyrean X-ray diffractometer equipped with a PIXcel $^{3 \mathrm{D}}$ detector and operated at $45 \mathrm{kV}$ and $40 \mathrm{kA}$ using $\mathrm{Cu} \mathrm{K} \alpha$ radiation $(\lambda=1.5418 \AA)$. All spectra were subjected to baseline correction using PeakFit1 4.12 software (Systat Software Inc., Chicago, IL) assuming Gaussian distribution function as the shape of the resolved peaks and Saviszky-Golay smoothing ${ }^{19}$. The crystallinity index (CrI) was determined by Segal method ${ }^{20}$. Thermogravimetric analysis (TGA) was performed using a Mettler Toledo model TGA/DSC 1.

\section{RESULTS AND DISCUSSION}

Pretreated biomass characteriation: IL performance was evaluated by measuring the glucose yields after enzymatic saccharification of these solids. The mass recovery, cellulose crystallinity, the lignin and glucan recoveries and ash contents of the pretreated, recovered substrates were investigated in an attempt to explain the differences in IL performance.

Suitability of pulp for enzymatic hydrolysis: A high glucose hydrolysis yield is an important marker of lignocellulose pretreatment quality. The glucose is regarded as the main product of the biorefinery and used in the fermentation to biofuels and other chemicals. Hence we compared the performance of the hydrogen sulfate ILs by carrying out an enzymatic saccharification assay on the recovered solid and benchmarked these yields against the $\left[\mathrm{C}_{2} \mathrm{C}_{1} \mathrm{im}\right][\mathrm{OAc}]: \mathrm{H}_{2} \mathrm{O}$ system.

Development of saccharification yields over time is shown in Figure 1. Figure 2 highlights the yields after 48 hours. At this point, all ILs performed better than the untreated biomass. The 4:1 $\left[\mathrm{C}_{2} \mathrm{C}_{1} \mathrm{im}\right][\mathrm{OAc}]:\left[\mathrm{H}_{2} \mathrm{O}\right]$ gave a yield of $59.7 \%(+/-1.1)$. Treatment with the diethyl-, triethyl- and diisopropylammonium ILs resulted in the highest saccharification yields. The best hydrogen sulfate ionic liquid was triethylammonium hydrogen sulfate, which resulted in a glucose yield of $45.0 \%(+/-$ 6.6). This represents a $75 \%$ efficacy compared to $\left[\mathrm{C}_{2} \mathrm{C}_{1} \mathrm{im}\right][\mathrm{OAc}]:\left[\mathrm{H}_{2} \mathrm{O}\right]$. Diethylammonium hydrogen sulfate also compared favorably at $67 \%$ of the $\left[\mathrm{C}_{2} \mathrm{C}_{1} \mathrm{im}\right][\mathrm{OAc}]:\left[\mathrm{H}_{2} \mathrm{O}\right]$ mixture. The 
diisopropylammonium IL was $60 \%$ as effective. The monoethylammonium and all three ethanolammonium ILs performed less well, with the best IL in this group only achieving 50\% as effective a pretreatment as the $\left[\mathrm{C}_{2} \mathrm{C}_{1} \mathrm{im}\right][\mathrm{OAc}]:\left[\mathrm{H}_{2} \mathrm{O}\right]$.

It thus appears that adding -OH groups to the cation reduces hydrolysis yield. It also appears that increasing the number of alkyl chains improved enzymatic hydrolysis yield. There was a step change between the mono- and disubstituted ammonium cations in both the simple and alcohol substituted cases, and then a more gradual increase from two to three alkyl chains. The ILs with disubstituted cations (diethyl-, diisopropyl- and diethanolammonium) were the most similar in performance. The performance of the diisopropylammonium IL indicates that steric effects do not play a part in hydrolysis efficacy, at least for cations with the short alkyl chain lengths ( $n=2-3)$.

Mass recovery: The mass recovered after pretreatment, washing and drying from the $\left[\mathrm{C}_{2} \mathrm{C}_{1} \mathrm{im}\right][\mathrm{OAc}]: \mathrm{H}_{2} \mathrm{O}$ mixture was $79 \%$. Recoveries for the hydrogen sulfate ILs compared to the benchmark system was similar or lower with a range of $57-78 \%$ mass recovered (Figure 3). No discernable trend was observed with varying alkyl chain number, or the addition of -OH groups to the IL cation. This suggests that other factors such as cellulose crystallinity or composition of the recovered solid may determine the saccharification yield.

Crystallinity: The crystallinity index of biomass treated with $\left[\mathrm{C}_{2} \mathrm{C}_{1} \mathrm{im}\right][\mathrm{OAc}]$ has been well documented to decrease, with the fibrillar structure of cellulose being broken up and the cellulose I structure converted to cellulose II. This phenomenon was not observed with biomass treated with the ammonium hydrogen sulfate ILs, where the crystallinity index increased slightly compared to untreated switchgrass (Table 2). An increase in crystallinity index is often indicative of hemicellulose and/or lignin removal and hydrogen sulfate ionic liquids have been shown to be effective delignification agents in other studies. ${ }^{3,15}$ Hence we investigated the composition of the recovered solid in more detail.

Glucan and lignin recovery: Lignin and glucan contents were measured using the acid hydrolysis method. They were then compared to the glucan and lignin in the untreated switchgrass to calculate the glucan and lignin recoveries (Figure 4). The amount of glucan found in the pretreated material was more or less the same for all ILs under the conditions applied. However, a reduced amount of lignin compared to the original biomass was observed for the diethyl-, triethyl- and diisopropylammonium ILs. These ILs also achieved the best enzymatic hydrolysis yields among the hydrogen sulfate ILs. This suggests that the ability to remove lignin (delignification) is an important trait of effective hydrogen sulfate ILs, while this is not necessary for $\left[\mathrm{C}_{2} \mathrm{C}_{1} \mathrm{im}\right][\mathrm{OAc}]$.

Surprisingly, for some ILs, lignin recoveries were substantially higher than the original lignin content. This was observed for monoethyl- and monoethanolammonium hydrogen sulfate, with lignin recoveries of 200 and $150 \%$, respectively. These ILs were also responsible for the lowest saccharification yields. We hypothesize that this is due to pseudolignin formation, which was observed previously for acidic solvents such as hydrogen sulfate based ILs. ${ }^{21-23}$ Pseudolignin is a yetto-be-defined substance or mixture of compounds that incorporates products of hemicellulose but is 
detected as lignin by the acid hydrolysis method. It appears that pseudolignin formation is detrimental to saccharification.

Ash and sulfur content: During compositional analysis, a significant variability of the ash content in the recovered solid was observed (Figure 5). Monoethylammonium IL and all the ethanolammonium ILs resulted in ash contents higher than in untreated switchgrass $(2.9 \%)$. More ash was present when the cation had fewer alkyl chains.

We further investigated the nature of the ash by measuring the sulfur content in the recovered biomass. Sulfur is indicative of the presence of the hydrogen sulfate anion. It is the only source for sulfur in the system, as biomass typically does not contain measurable quantities of sulfur. As hypothesized, some of the material recovered after hydrogen sulfate IL treatment was found to contain sulfur (Figure 5), while the $\left[\mathrm{C}_{2} \mathrm{C}_{1} \mathrm{im}\right][\mathrm{OAc}]$ treated biomass showed no sulfur content.

The quantity of sulfur and the ash content appeared to be correlated. The sulfur content was higher for samples that had higher ash contents. Lower quantities were noted for the alkylammonium hydrogen sulfate ILs. The sulfur levels in biomass treated with trisubsitituted triethylammonium hydrogen sulfate and the bulkier disubstituted diisopropylammonium hydrogen sulfate were below the detection limit, corresponding to $<0.3 \mathrm{w} / \mathrm{w}[\%]$. High sulfur and ash contents also seemed to coincide with excess recovery of lignin/pseudolignin formation (Figure 4 and 5).

Incorporation of sulfur could be caused by incomplete removal of IL, but the biomass washing procedure was quite exhaustive, so we hypothesize that the sulfur may be bound chemically. We are currently investigating the mechanism for the sulfur absorption into the pretreated solid. This may also confirm the reason for the significant differences in sulfur contents. For example, the differences could be due to the cation size (smaller ILs having more sulfur per unit volume) or it could be a kinetic effect.

In summary, it was found that lower ash and sulfur content correlated with reduction in lignin content and better glucose yield upon enzymatic saccharification.

IL thermal stability: An important requirement of ILs employed in industrial processes is that they must be recoverable for repeated use. This requires them to be structurally stable under processing conditions. For ILs based on organic cations such as the ones investigated in this study, typical degradation processes are the loss of alkyl chains from the cation (dealkylation) followed by a number of other reactions as the temperature approaches the range where $\mathrm{C}-\mathrm{C}$ and $\mathrm{C}-\mathrm{H}$ bonds break. The benchmark IL $\left[\mathrm{C}_{2} \mathrm{C}_{1} \mathrm{im}\right][\mathrm{OAc}]$ has been shown to be problematic in this respect. ${ }^{11}$

In order to investigate the thermal stabilities of the ILs applied in this study and compare them with $\left[\mathrm{C}_{2} \mathrm{C}_{1} \mathrm{im}\right][\mathrm{OAc}]$, TGA analysis was carried out. The values resulting from the TGA analysis, $\mathrm{T}_{\mathrm{PEAK}}$ and $\mathrm{T}_{\text {ONSET }}$, are shown in Table 3. It shows that $\mathrm{T}_{\text {PEAK }}$ was 322,301 and $290{ }^{\circ} \mathrm{C}$ for the mono-, diand triethylammonium ILs, respectively. These thermal stabilities appear to trend with electron density on the nitrogen of the ammonium group. There was also a trend in decreasing thermal stability with increasing hydroxyethyl chain number, with $\mathrm{T}_{\mathrm{PEAK}}$ of $306,294,294^{\circ} \mathrm{C}$ for the mono-, 
di- and triethanolammonium ILs, respectively. The diisopropylammonium cation showed the lowest $\mathrm{T}_{\text {PEAK }}$ at $280{ }^{\circ} \mathrm{C}$, which could be due to a higher prevalence of Hoffmann dealkylation for the branched alkyl chains as compared to the substitution reaction that is observed for linear alkyl substituents. $^{24}$

Overall, TGA analysis suggests that decomposition of all hydrogen sulfate ILs occurs at substantially higher temperatures than that of $\left[\mathrm{C}_{2} \mathrm{C}_{1} \mathrm{im}\right][\mathrm{OAc}]$, for which a $\mathrm{T}_{\text {ONSET }}$ of $215^{\circ} \mathrm{C}$ has been measured. ${ }^{11}$ Similarly, the protic acetate ILs that were recently shown to delignify biomass also suffer from very low stabilities in the TGA. ${ }^{25}$ This is likely due to incomplete protonation of the amines by acetic acid rather than loss of alkyl chains. This 'volatility' will require protic acetate ILs to be contained during treatment. In contrast, the high stability of the protic ammonium hydrogen sulfate complexes will avoid occurrence of hazardous vapors and explosions and structural damage to the cation.

Despite this, it should be noted that long term stabilities for ionic liquids are considerably lower than $\mathrm{T}_{\text {ONSET }}$ and $\mathrm{T}_{\text {PEAK }}$ values would suggest, ${ }^{11,26,27}$ and hence biomass processing temperatures should also be lower. For example, dealkylation reactions have been observed for $\left[\mathrm{C}_{2} \mathrm{C}_{1} \mathrm{im}\right][\mathrm{OAc}]$ at temperatures as low as $120^{\circ} \mathrm{C}$.

We also would like to highlight that the chemical nature of the degradation products should be considered. It is noteworthy that the likely "impurities" generated by dealkylation of tri- and dialkylammonium hydrogen sulfate ILs will be less substituted ammonium cations. For example the dealkylation product of triethylammonium hydrogen sulfate will be diethylammonium ethyl sulfate (Scheme 1). The anion can then hydrolyze to ethanol and $\mathrm{HSO}_{4}$. Since di- and monoalkylated ammonium ILs still performed well in this study, the reduction in performance due to the presence of dealkylation products is likely to be slight. In summary, the alkylammonium hydrogen sulfate ILs exhibit high thermal stabilities that are much greater than the benchmark system. This suggests that long-term use in a continuous process will be feasible.

Technoeconomic analysis: In order to demonstrate the effect of a lowered ionic liquid price on the economics of ethanol production, we made use of a previously published process model. ${ }^{12}$ This model was originally used to study the effect of IL price, recycling, and loading on the economics of ethanol production. It includes the unit operations needed to produce ethanol from corn stover and assumes ionic liquid pretreatment based on a generalized protocol. It solves the material and energy balances associated with ethanol production, and uses the results of these balances to perform a cost estimation. The cost estimation is then used to calculate other economic parameters such as the capital cost, the operating cost, the net present value of the investment, etc. The IL price applied here was taken from our recent techno-economic model that estimated the cost of bulk production of two protic hydrogen sulfate ionic liquids. ${ }^{14}$ Given the $\left[\mathrm{HNEt}_{3}\right]\left[\mathrm{HSO}_{4}\right]$ sulfate cost of $\$ 1.24 \mathrm{~kg}^{-1}$, the process model was used to calculate the effect of lowering the IL price from $\$ 50 \mathrm{~kg}^{-1}$ (a price often associated with ILs used for pretreatment) to $\$ 1.25 \mathrm{~kg}^{-1}$ on the minimum ethanol selling price (MESP). The MESP is the price of the biofuel that would make the net present value of the ethanol facility equal to zero over its 25 -year lifetime. The financial assumptions (discount rate, debt-equity split, loan interest, etc.) were left unchanged compared to the previous study. 
The results of the analysis are illustrated in Figure 6, which shows the effects on the MESP for a range of IL recycle rates and IL/biomass ratios at IL cost of $\$ 50 \mathrm{~kg}^{-1}$ and $\$ 1.25 \mathrm{~kg}^{-1}$. At high IL prices, e.g. at an IL purchasing price of $\$ 50 \mathrm{~kg}^{-1}$, the MESP was $>\$ 6 \mathrm{gal}^{-1}$, even when assuming a very high IL recycle rate of $99.6 \%$, and 1:1 IL/biomass loading, versus $\$ 3.22 \mathrm{gal}^{-1}$ for an IL cost of $\$ 1.25$ $\mathrm{kg}^{-1}$. This is close to the MESP that has been calculated for dilute acid pretreatment of corn stover, $\$ 2.15 \mathrm{gal}^{-1}$. $^{28}$

Looking at the cost structure more closely it becomes clear that the IL price impacted the MESP so much because of the fraction of the annual operating cost devoted to purchasing make up IL for replacing the non-recovered IL. For example, at an IL purchasing price of $\$ 50 \mathrm{~kg}^{-1}, 64 \%$ of the raw material cost were due to the ionic liquid (the remainder of the raw material cost being the lignocellulosic feedstock), whereas an IL price of $\$ 1.25 \mathrm{~kg}^{-1}$ reduced the IL contribution to the raw material cost to $4.2 \%$. This is the main reason for addressing IL price as a primary design criterion. Fortunately, this study shows that IL cost can be mitigated by careful design of the IL.

A note on IL toxicity: Toxicity is an important consideration before commercialization of a process employing chemicals. The toxicity of the newly investigated ILs is not yet known. ${ }^{29}$ However, due to their rather simple construction from an acid and a base, we expect a similar toxicity as the parent amine and acid.

Amine toxicity depends on chain length (longer alkyl chains increase toxicity), so this can be minimized by choosing shorter chain alkylamines such as we have done here. We'd like to point out that triethylamine does not bioaccumulate and the highest toxicity potential of triethylamine is through inhalation, which is vastly reduced when bound in an ionic complex. The high decomposition temperatures (above $280^{\circ} \mathrm{C}$ ) demonstrate that the amines are not volatilized in a wide temperature window, while this is likely to be an issue for protic ILs made from amines and weak bases such as acetic acid.

The hydrogen sulfate anion should not be toxic in dilute form. Regarding corrosiveness, the hydrogen sulfate salts are acidic $\left(\mathrm{pK}_{\mathrm{a}}\right.$ of the $\mathrm{HSO}_{4}{ }^{-}$anion in dilute solution is $\sim 2$ ), however, they are significantly less so than concentrated sulfuric acid and other strong acids. Corrosion could be a concern for process safety and equipment compatibility and needs to be considered in more detailed impact assessments.

\section{CONCLUSIONS}

We have designed and synthesized a series of new protic ionic liquids based upon the $\left[\mathrm{HSO}_{4}\right]$ anion and examined their effectiveness as pretreatment solvents for switchgrass. The new ILs were examined for their ability to enhance enzymatic saccharification yields, their stability and their potential for remaining in the biomass product streams. We demonstrated that good yields can be achieved with some of these investigated ILs. The most effective solvent was approximately $75 \%$ as efficient at increasing cellulose digestibility as the benchmark IL $\left[\mathrm{C}_{2} \mathrm{C}_{1} \mathrm{im}\right][\mathrm{OAc}]$, at a fraction of the proposed bulk production cost and better thermal stability, while leaving low levels of residual IL in the cellulose pulp. 
The mode of enhanced saccharification yield for the alkylammonium ILs was shown to be through lignin removal, but not decrystallization, of cellulose. This demonstrates that high enzymatic hydrolysis kinetics can be achieved in the absence of cellulose decrystallization. This also indicates that the cellulose pulps isolated this way may be used for applications where highly crystalline cellulose would be desired.

The process that is associated with the use of these hydrous ammonium hydrogen sulfate ILs also greatly simplifies biomass processing - the recovery of the biomass pulps by filtration or centrifugation without the need for antisolvent precipitation offers an inherent processing benefit as it reduces organic solvent and water usage.

In addition, the high thermal stability of the ILs employed will reduce solvent degradation and the associated waste. Therefore, with room for optimization, and a low cost synthesis route established, this study demonstrates that IL cost is no longer an impediment to its use in the biorefinery concept. 
Scheme 1: Dealkylation of triethylammonium hydrogen sulfate

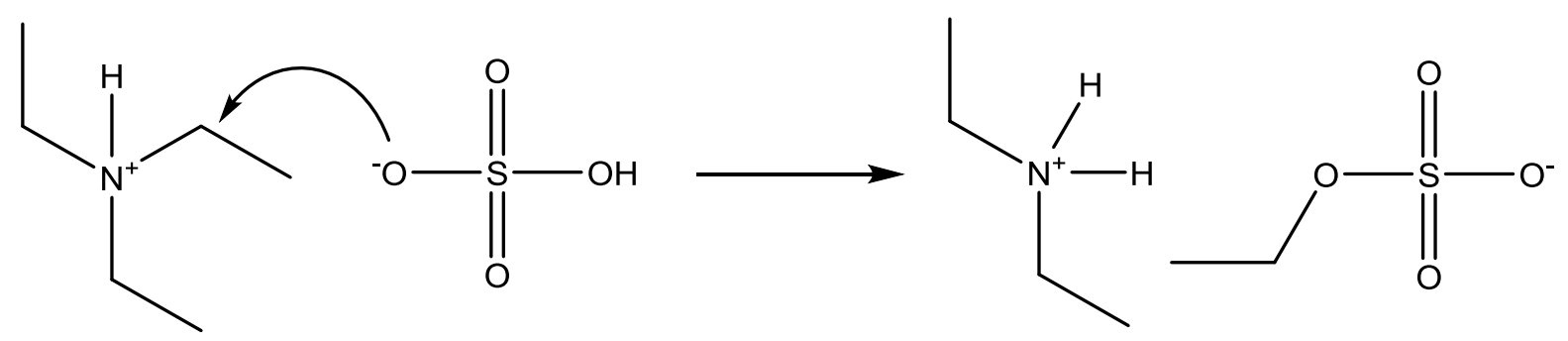

Table 1. Chemical structure of designed ionic liquid cations, with an $[\mathrm{HSO}]_{4}{ }^{-}$anion.

diethanolammonium


Table 2 Crystallinty index of recovered biomass after treatment with ionic liquids

\begin{tabular}{ll}
\hline Pretreatment solvent & Crystallinity Index \\
\hline Untreated switchgrass & 0.31 \\
{$\left[\mathrm{C}_{2} \mathrm{C}_{1}\right.$ im] $[\mathrm{OAc}]$} & 0.08 \\
Monoethylammonium & 0.42 \\
Diethylammonium & 0.38 \\
Triethylammonium & 0.41 \\
Monoethanolammonium & 0.36 \\
Diethanolammonium & 0.35 \\
Triethanolammonium & 0.31 \\
Diisopropylammonium & 0.33 \\
\hline
\end{tabular}


Table 3. Thermal stabilities of IL, denoting the onset of decomposition $\mathrm{T}_{\text {ONSET }}$ and the peak decomposition temperature, $\mathrm{T}_{\mathrm{PEAK}}$.

\begin{tabular}{lll}
\hline & $\mathrm{T}_{\text {ONSET }} /\left[{ }^{\circ} \mathrm{C}\right]$ & $\mathrm{T}_{\text {PEAK }} /\left[{ }^{\circ} \mathrm{C}\right]$ \\
\hline Monoethylammonium & 294 & 322 \\
Diethylammonium & 281 & 301 \\
Triethylammonium & 277 & 290 \\
Monoethanolammonium & 299 & 306 \\
Diethanolammonium & 289 & 294 \\
Triethanolammonium & 278 & 294 \\
Diisopropylammonium & 269 & 280 \\
\hline
\end{tabular}




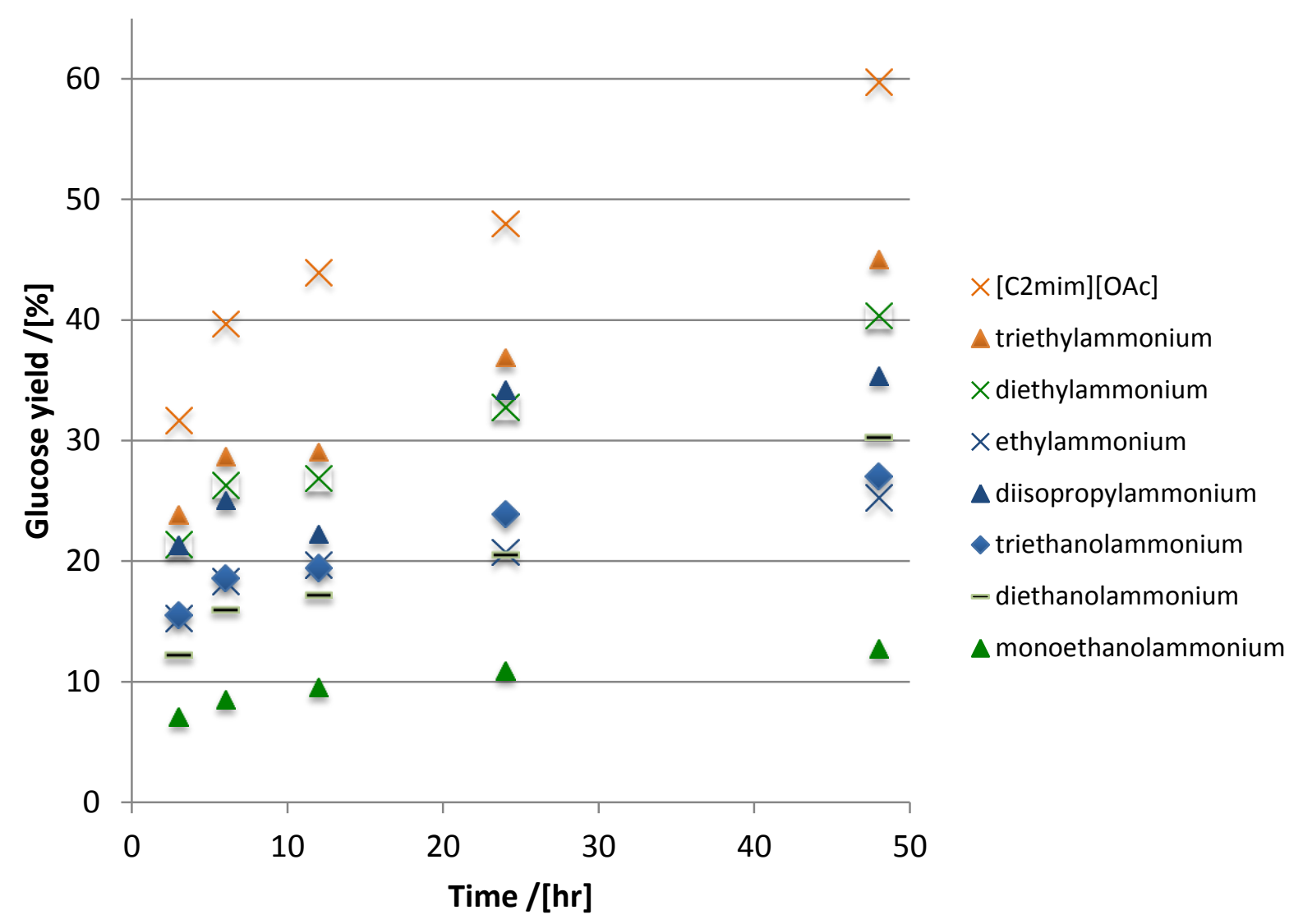

Figure 1. Enzymatic hydrolysis kinetics up to 48 hours. Glucose yield was the amount of glucose released into the hydrolysate relative to the glucan that was present in the recovered pretreated biomass. 


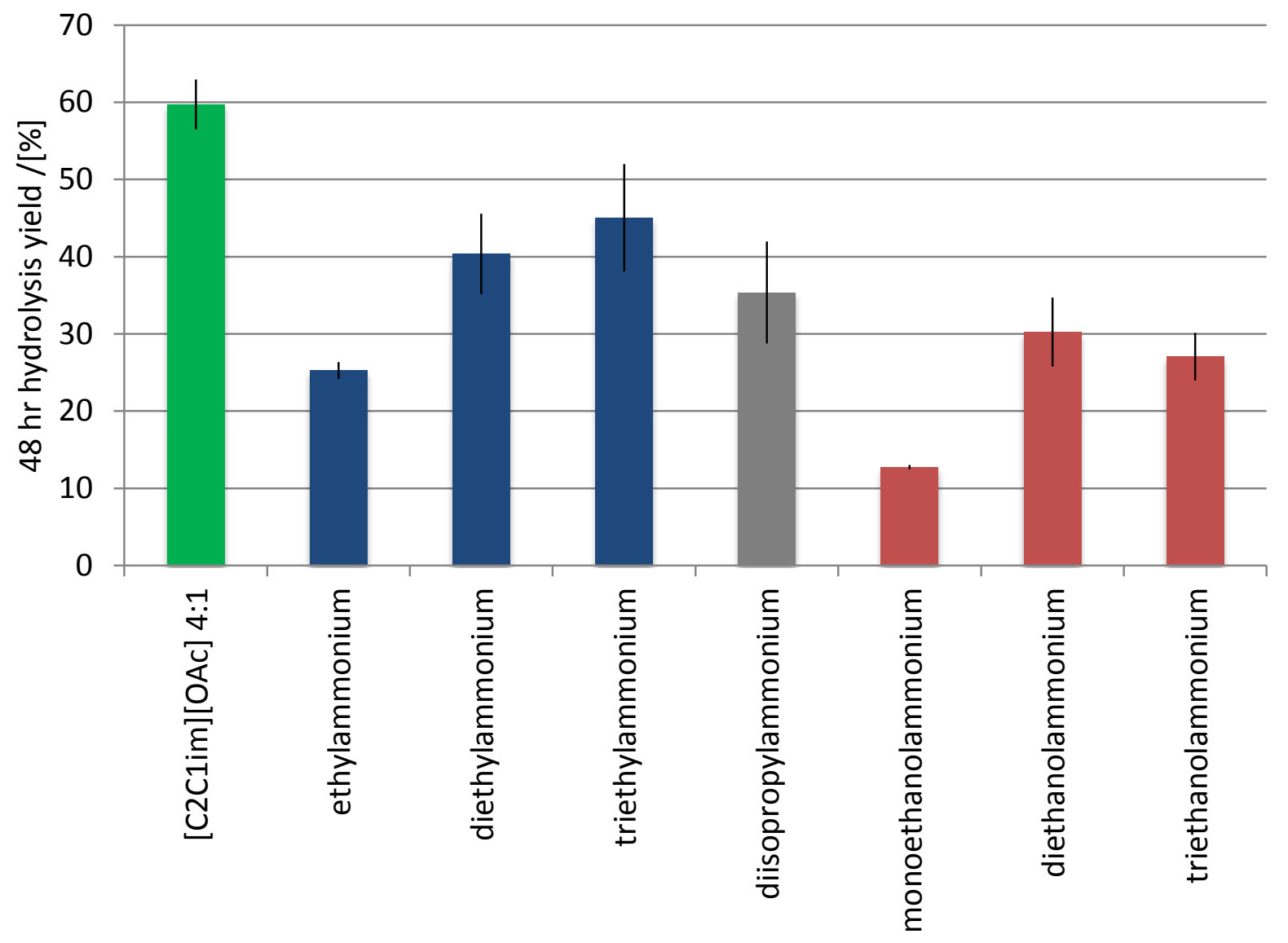

Figure 2. Glucose yield after 48 hour enzymatic hydrolysis (relative to glucan content in the pretreated biomas 



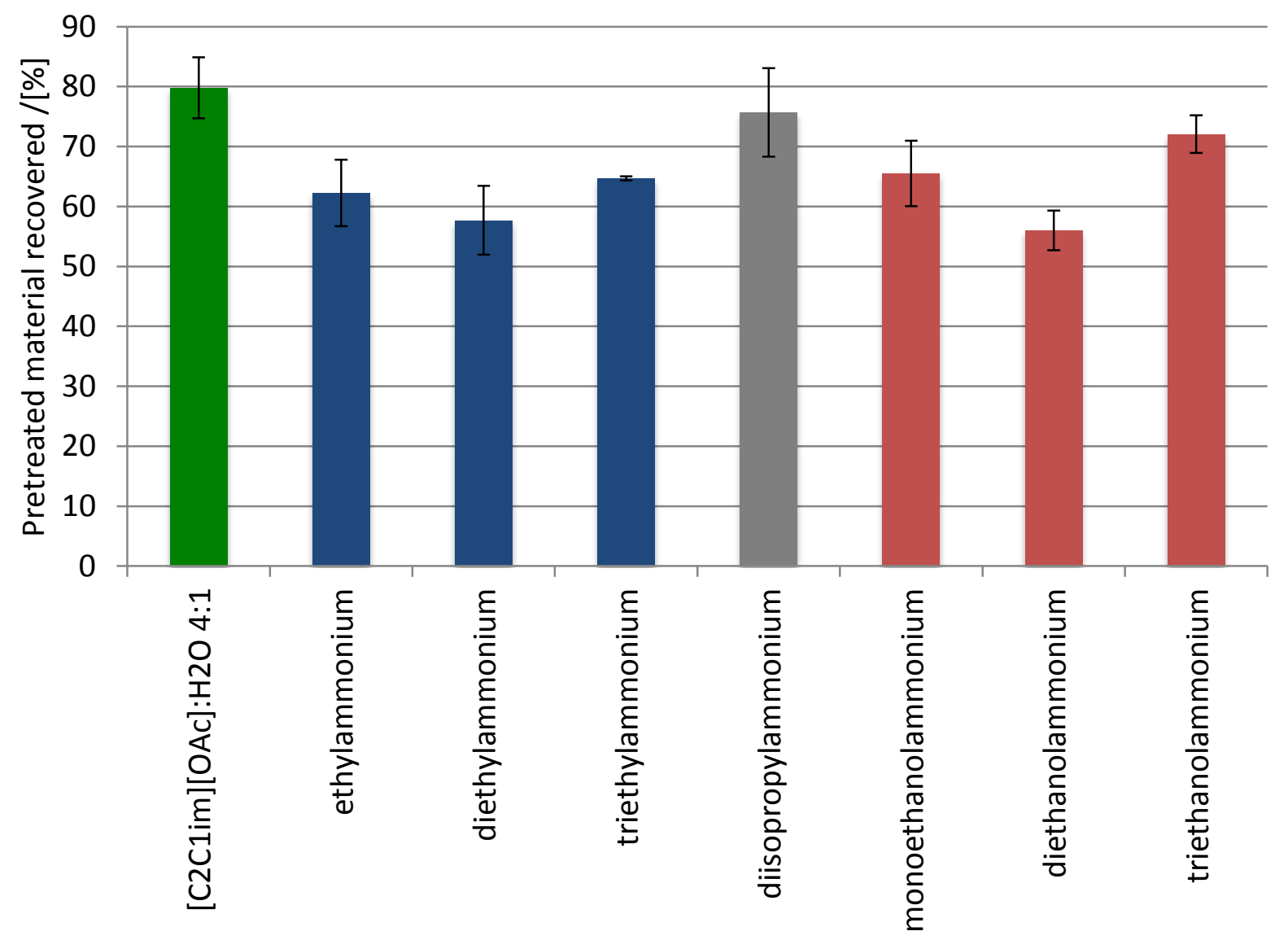

Figure 3. Percentage material recovered as solid post-pretreatment

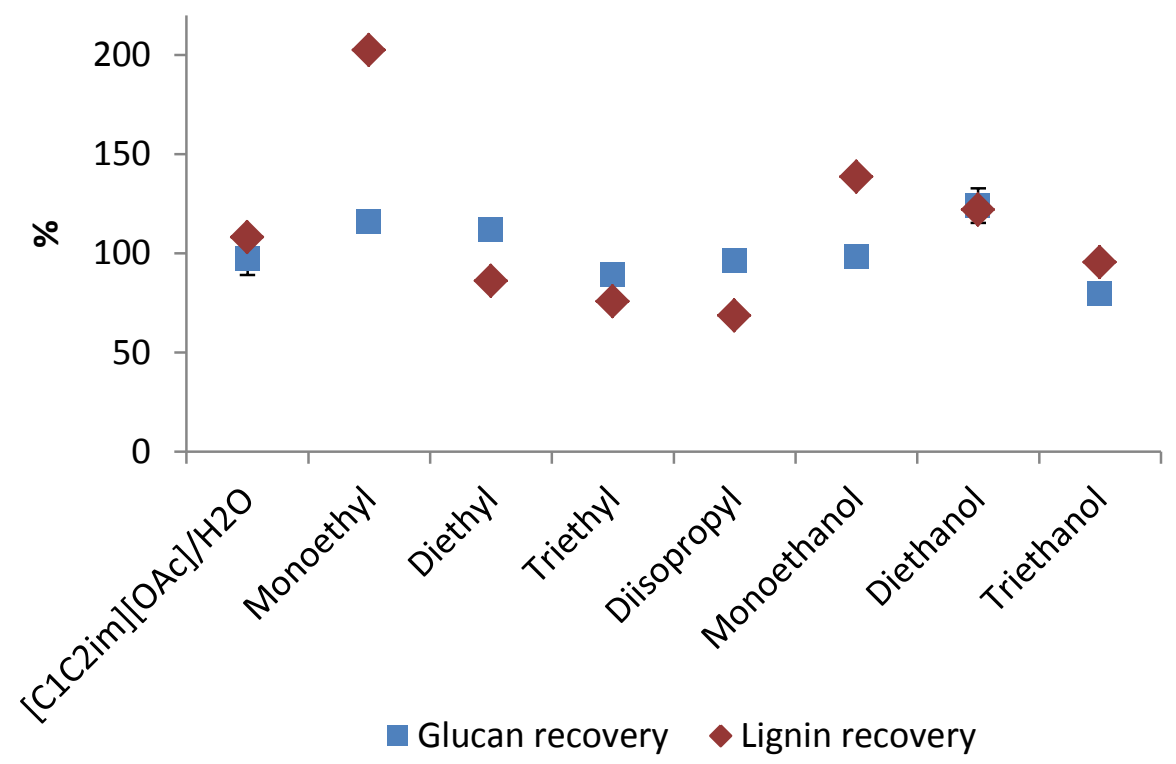

Figure 4 Glucan and lignin recovery in pretreated material prior to enzymatic hydrolysis. 


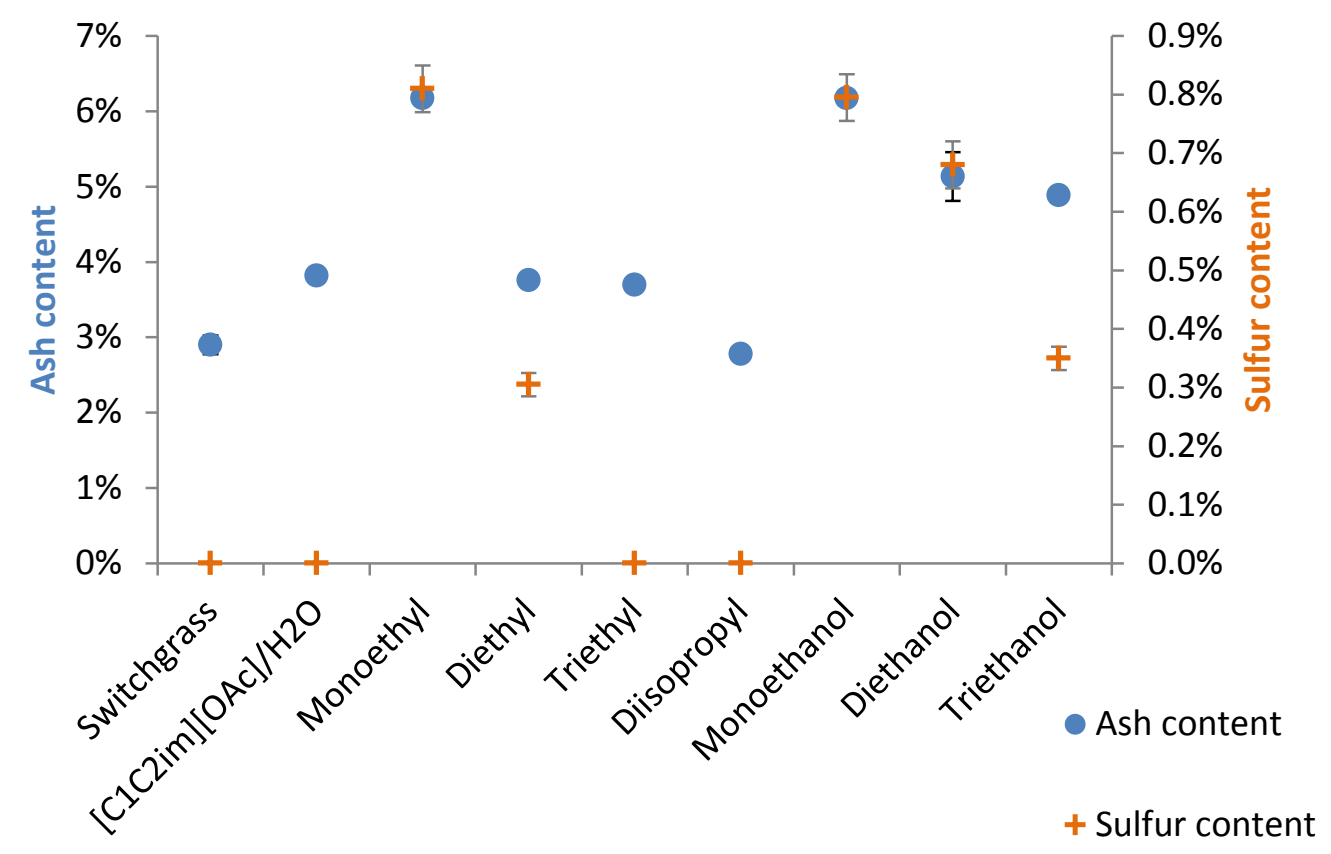

Figure 5. Ash and sulfur content in pretreated material w/w [\%]
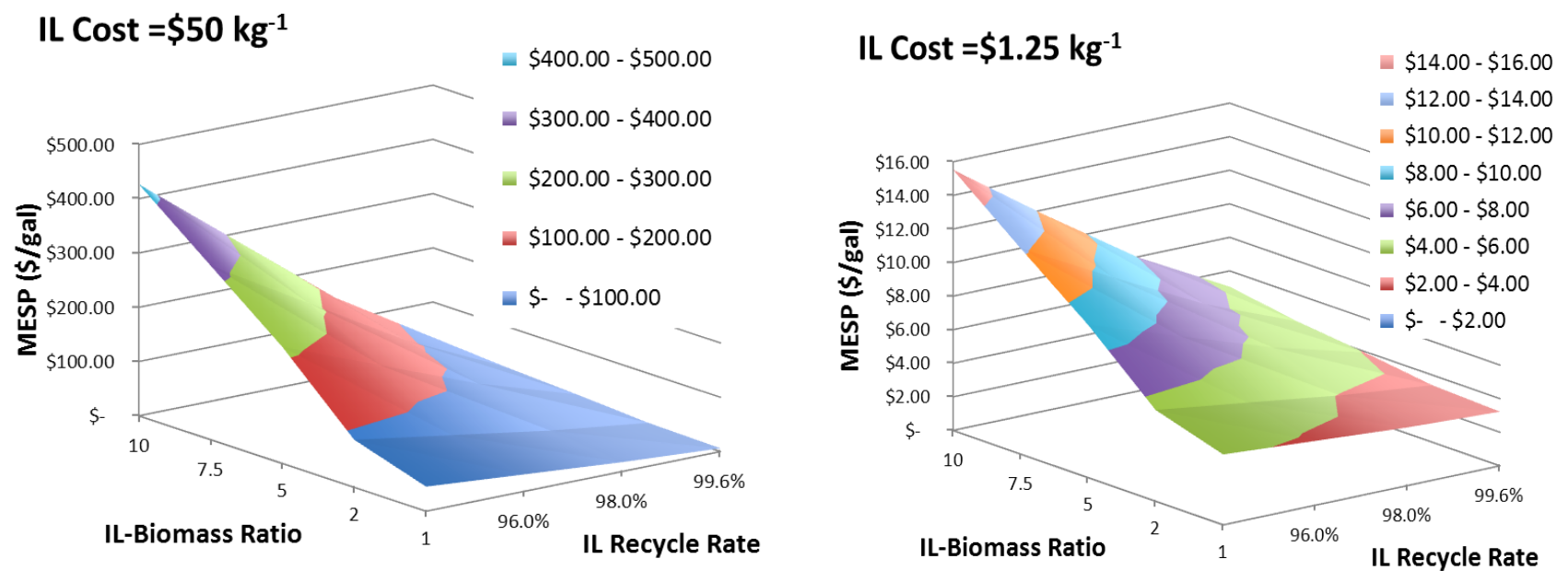

Figure 6. Influence of IL-biomass ratio and IL recycle rate on MESP when the IL price is $\$ 50 / \mathrm{kg}$ and $\$ 1.25 / \mathrm{kg}$ on MESP 


\section{ACKNOWLEDGEMENTS}

This work conducted by the Joint BioEnergy Institute was supported by the Office of Science, Office of Biological and Environmental Research, of the U.S. Department of Energy under Contract No. DE-AC02$05 \mathrm{CH} 11231$.

\section{REFERENCES}

1. H. W. Blanch, B. A. Simmons and D. Klein-Marcuschamer, Biotechnol. J., 2011, 6, 1086-1102.

2. S. P. Chundawat, G. T. Beckham, M. E. Himmel and B. E. Dale, Annu. Rev. Chem. Biomol. Eng., 2011, 2, 121-145.

3. A. Brandt, M. J. Ray, T. Q. To, D. J. Leak, R. J. Murphy and T. Welton, Green Chem., 2011, 13, 2489-2499.

4. N. Uppugundla, L. da Costa Sousa, S. Chundawat, X. Yu, B. Simmons, S. Singh, X. Gao, R. Kumar, C. Wyman, B. Dale and V. Balan, Biotechnol. Biofuels, 2014, 7, 72.

5. X. Gao, R. Kumar, S. Singh, B. Simmons, V. Balan, B. Dale and C. Wyman, Biotechnol. Biofuels, 2014, 7, 71.

6. A. Brandt, J. P. Hallett, D. J. Leak, R. J. Murphy and T. Welton, Green Chem., 2010, 12, 672-679.

7. Ö. P. Çetinkol, D. C. Dibble, G. Cheng, M. S. Kent, B. Knierim, M. Auer, D. E. Wemmer, J. G. Pelton, Y. B. Melnichenko and J. Ralph, Biofuels, 2010, 1, 33-46.

8. J. Shi, V. S. Thompson, N. A. Yancey, V. Stavila, B. A. Simmons and S. Singh, Biofuels, 2013, 4, 6372.

9. D. Groff, A. George, N. Sun, N. Sathitsuksanoh, G. Bokinsky, B. A. Simmons, B. M. Holmes and J. D. Keasling, Green Chem., 2013, 15, 1264-1267.

10. G. Bokinsky, P. P. Peralta-Yahya, A. George, B. M. Holmes, E. J. Steen, J. Dietrich, T. S. Lee, D. Tullman-Ercek, C. A. Voigt and B. A. Simmons, Proc. Nat. Acad. Sci., 2011, 108, 19949-19954.

11. M. T. Clough, K. Geyer, P. A. Hunt, J. Mertes and T. Welton, Phys. Chem. Chem. Phys., 2013, 15, 20480-20495.

12. D. Klein-Marcuschamer, B. A. Simmons and H. W. Blanch, Biofuels, Bioprod. Bioref., 2011, 5, 562569.

13. J. P. Hallett and T. Welton, Chem. Rev., 2011, 111, 3508-3576.

14. L. Chen, M. Sharifzadeh, N. Mac Dowell, T. Welton, N. Shah and J. P. Hallett, Green Chem., 2014, 16, 3098-3106.

15. P. Verdía, A. Brandt, J. P. Hallett, M. J. Ray and T. Welton, Green Chem., 2014, 16, 1617-1627.

16. N. Sathitsuksanoh, K. M. Holtman, D. J. Yelle, T. Morgan, V. Stavila, J. Pelton, H. Blanch, B. A. Simmons and A. George, Green Chem., 2014.

17. G. Moxley and Y.-H. P. Zhang, Energy Fuels, 2007, 21, 3684 - 3688.

18. A. Sluiter, B. Hames, R. Ruiz, C. Scarlata, J. Sluiter, D. Templeton and D. Crocker, in Technical Report. NREL/TP-510-42618., 2011.

19. N. Sathitsuksanoh, Z. Zhu, S. Wi and Y.-H. P. Zhang, Biotechnol. Bioeng., 2011, 108, 521-529.

20. L. Segal, J. Creely, A. Martin Jr and C. Conrad, Text. Res. J. , 1959, 29, 786.

21. R. Kumar, F. Hu, P. Sannigrahi, S. Jung, A. J. Ragauskas and C. E. Wyman, Biotechnol. bioeng., 2013, 110, 737-753.

22. F. Hu, S. Jung and A. Ragauskas, Bioresour. Technol., 2012, 117, 7-12.

23. P. Sannigrahi, D. H. Kim, S. Jung and A. Ragauskas, Energy Environ. Sci., 2011, 4, 1306-1310.

24. P. J. Scammells, J. L. Scott and R. D. Singer, Austral. J. Chem., 2005, 58, 155-169.

25. E. C. Achinivu, R. M. Howard, G. Li, H. Gracz and W. A. Henderson, Green Chem., 2014, 16, 11141119. 
26. D. M. Fox, W. H. Awad, J. W. Gilman, P. H. Maupin, H. C. De Long and P. C. Trulove, Green Chem., 2003, 5, 724-727.

27. K. J. Baranyai, G. B. Deacon, D. R. MacFarlane, J. M. Pringle and J. L. Scott, Austral. J. Chem., 2004, 57, 145-147.

28. D. Humbird, R. Davis, L. Tao, C. Kinchin, D. Hsu, A. Aden, P. Schoen, J. Lukas, B. Olthof, M. Worley and D. D. Sexton, D., Process design and economics for biochemical conversion of lignocellulosic biomass to ethanol, NREL/TP-510-47764, 2011.

29. K. S. Egorova and V. Ananikov, ChemSusChem, 2014, 7. 